\title{
Long-term, open-labeled extension study of idursulfase in the treatment of Hunter syndrome
}

\author{
Joseph Muenzer, $M D, P h D^{l}$, Michael Beck, $M D^{2}$, Christine M. Eng, $M D^{3}$, Roberto Giugliani, MD, $P h D^{4}$, \\ Paul Harmatz, $M D^{5}$, Rick Martin, $M D^{6}$, Uma Ramaswami, $M D^{7}$, Ashok Vellodi, $M D^{8}$, \\ James E. Wraith, $M D^{9}$, Maureen Cleary, $M D^{8}$, Muge Gucsavas-Calikoglu, MD, $M P H^{1}$, \\ Ana Cristina Puga, MD, PhD ${ }^{10}$, Marwan Shinawi, MD, FACMG ${ }^{3}$, Birgit Ulbrich, $M D^{7}$, \\ Suresh Vijayaraghavan, $M D^{11}$, Susanne Wendt, $M D^{2}$, Anne Marie Conway, $M H A, R N^{6}$, Alexandra Rossi, $B S^{6}$, \\ David A. H. Whiteman, $M D^{6}$, and Alan Kimura, MD, $P h D^{12}$
}

\begin{abstract}
Purpose: This study evaluated the safety and effectiveness of long-term enzyme replacement therapy with idursulfase (recombinant human iduronate-2-sulfatase) in patients with Hunter syndrome. Methods: All 94 patients who completed a 53-week double-blinded study of idursulfase enrolled in this open-labeled extension study and received intravenous idursulfase at a dose of $0.5 \mathrm{mg} / \mathrm{kg}$ weekly for 2 years, and clinical
\end{abstract}

From the ${ }^{1}$ Department of Pediatrics, University of North Carolina at Chapel Hill, Chapel Hill, North Carolina; ${ }^{2}$ Department of Pediatrics, University Medical Center, University of Mainz, Mainz, Germany; ${ }^{3}$ Baylor College of Medicine, Houston, Texas; ${ }^{4}$ Department of Genetics/UFRGS, Medical Genetics Service/ HCPA and INAGEMP, Porto Alegre, RS, Brazil; ${ }^{5}$ Department of Gastroenterology and Nutrition, Children's Hospital \& Research Center Oakland, Oakland, California; ${ }^{6}$ Shire Human Genetic Therapies, Inc., Cambridge, Massachusetts; ${ }^{7}$ Pediatric Metabolic Unit, Cambridge University Teaching Hospitals, Cambridge; ${ }^{8}$ Metabolic Unit, Great Ormond Street Hospital for Children NHS Trust, London; 'Willink Biochemical Genetics Unit, Royal Manchester Children's Hospital, Manchester, United Kingdom; ${ }^{10}$ Clinical Research, Genzyme Europe B.V., Naarden, The Netherlands; ${ }^{11}$ Inherited Metabolic Disease Unit, Birmingham Children's Hospital, Birmingham, United Kingdom; and ${ }^{12}$ Clinical Development, Novartis Vaccines and Diagnostics, Cambridge, Massachusetts.

Joseph Muenzer, MD, PhD, Department of Pediatrics, CB 7487, Medical School Wing E Room 117, University of North Carolina at Chapel Hill, Chapel Hill, NC 27599-7487. E-mail: muenzer@med.unc.edu.

Disclosure: Drs. Muenzer and Wraith have received honoraria, travel grants, and/or research grants from Shire HGT and Genzyme Corporation. Dr. Beck has received travel support, honoraria, and unrestricted grants from Shire HGT, Genzyme Corporation, and Biomarin. Dr. Eng has served as Principal Investigator for clinical trials sponsored by Shire HGT and Genzyme Corporation, who provided institutional research grants to support the studies. Dr. Eng has also received consultancy fees and speakers bureau fees from Shire HGT and Genzyme Corporation. Dr. Giugliani has received travel grants and/or speaker's fees from Shire HGT and Genzyme Corporation. Dr. Harmatz reports receiving honoraria, travel grants, consulting, and/or research support from Shire HGT, Genzyme Corporation, and Biomarin. Dr. Martin, Ms. Conway, Ms. Rossi, and Dr. Whiteman are employees of Shire HGT. Dr. Ramaswami has received travel grants, research support, and honoraria for invited lectures from Shire HGT and Genzyme Corporation. Dr. Vellodi reports receiving honoraria, research support, and/or travel grants from Shire HGT. Dr. Cleary has attended conferences organized and funded by Shire HGT. Dr. Puga has received research funding from Shire HGT and is currently an employee of Genzyme Corporation. Dr. Wendt has received research support and travel grants from Shire HGT. Dr. Kimura was an employee of Shire HGT at the time of the planning and initial conduct of this study. Drs. Vijayaraghavan, Gucsavas-Calikoglu, Ulbrich, and Shinawi have no conflicts to disclose.

Joseph Muenzer was the lead investigator of this clinical trial. Joseph Muenzer, Michael Beck, Christine M. Eng, Roberto Giugliani, Paul Harmatz, Rick Martin, Uma Ramaswami, Ashok Vellodi, and James E. Wraith are the study site principal investigators.

At the time of the study, Dr. Puga was affiliated with the Department of Genetics/UFRGS, Medical Genetics Service/HCPA and INAGEMP, Porto Alegre, RS, Brazil; Dr. Martin was affiliated with St. Louis Children's Hospital, St. Louis, MO; and Dr. Kimura was affiliated with Shire Human Genetic Therapies, Inc., Cambridge, MA. outcomes and safety were assessed. Results: No change in percent predicted forced vital capacity was seen, but absolute forced vital capacity demonstrated sustained improvement and was increased $25.1 \%$ at the end of the study. Statistically significant increases in 6-minute walking test distance were observed at most time points. Mean liver and spleen volumes remained reduced throughout the 2-year extension study. Mean joint range of motion improved for the shoulder and remained stable in other joints. Both the parent- and child-assessed Child Health Assessment Questionnaire Disability Index Score demonstrated significant improvement. Infusion-related adverse events occurred in 53\% of patients and peaked at Month 3 of treatment and declined thereafter. Neutralizing $\operatorname{IgG}$ antibodies were detected in $23 \%$ of patients and seemed to attenuate the improvement in pulmonary function. Conclusions: Weekly infusions of idursulfase result in sustained clinical improvement during 3 years of treatment. Genet Med 2011:13(2):95-101.

Key Words: Hunter syndrome, idursulfase, enzyme replacement therapy, clinical trial, lysosomal storage disease, mucopolysaccharidosis type II

M ucopolysaccharidosis II (Hunter syndrome) is a rare Xlinked metabolic disorder caused by a deficiency of the lysosomal enzyme iduronate-2-sulfatase. ${ }^{1}$ This enzyme catalyzes a step in the catabolism of glycosaminoglycans (GAGs), ${ }^{2}$ and its deficiency causes accumulation of GAGs in tissues and organs of affected individuals. Hunter syndrome has an estimated prevalence of approximately 1 in 170,000 male live births. ${ }^{3}$ The clinical phenotype involves many organs and systems and has been described in detail elsewhere. ${ }^{3}$ The phenotype is variable in both its onset and severity. Patients typically appear normal at birth with signs and symptoms emerging between 2 and 4 years of age. ${ }^{2}$ Patients with a severe phenotype exhibit somatic symptoms between the ages of 2 and 4 years with neurologic deficits and cognitive impairment appearing before the age of 6 years. Death typically occurs in the first or second decade of life for patients with the severe phenotype. Patients with an attenuated phenotype have minimal central neurologic involvement and always develop somatic disease. These patients typically survive into adulthood with normal intelligence.

Recombinant human idursulfase was approved for enzyme replacement therapy (ERT) of Hunter syndrome in 2006. In the pivotal clinical trial, a randomized, double-blinded, placebocontrolled study, patients were treated with intravenous infu-

Submitted for publication June 14, 2010.

Accepted for publication September 25, 2010

Published online ahead of print December 10, 2010.

DOI: $10.1097 /$ GIM.0b013e3181fea459 
sions of idursulfase $(0.5 \mathrm{mg} / \mathrm{kg})$ once weekly or every other week (EOW), or with placebo infusions (weekly) for 1 year. ${ }^{4}$ Significant functional improvement was found in both idursulfase treatment groups compared with placebo, as determined from a composite endpoint of the sum of the ranks of changes in 6-minute walk test (6MWT) distance and percent of predicted forced vital capacity (FVC). ${ }^{4}$ Other important findings included significant reductions in spleen and liver size and improvement in absolute FVC. The most common drug-associated adverse events (AEs) were infusion-related reactions and included headache, urticaria, and pyrexia. In this study, we describe the open-labeled extension of that study. Results indicate that idursulfase treatment produced long-term improvements and stabilization of clinical disease.

\section{MATERIALS AND METHODS}

All 94 patients who completed the 53-week, double-blinded study enrolled in the extension study and were treated weekly with idursulfase (Elaprase ${ }^{\circledR}$, Shire Human Genetic Therapies, Inc., Cambridge, MA) at a dose of $0.5 \mathrm{mg} / \mathrm{kg}$ intravenously. Thus, patients who were in the active treatment groups of the doubleblinded study were treated with idursulfase for a total of 36 months, and the patients in the placebo group of the double-blinded study were treated with idursulfase for a total of 24 months. Because of the requirement to participate in the testing procedures, patients with a severe phenotype were excluded from both the original double-blinded study ${ }^{4}$ and, thus, from this open-labeled extension study. The enzyme was diluted to final volume of 100 $\mathrm{mL}$ using normal saline and infused over a period of approximately 3 hours. If a patient developed an infusion reaction (typically chills, fever, headache, and/or flushing), the following actions were taken: (a) if it was the first occurrence, the infusion was stopped and not restarted; (b) for subsequent infusions, the patient was pretreated with an antihistamine and/or corticosteroid; and (c) if the reactions still occurred, the infusion was stopped and restarted when the reaction had resolved.

\section{Study design}

This study was a multicentered, multinational, open-labeled clinical trial. The study was conducted in compliance with international guidelines and appropriate local and country regulations. The protocol and informed consent documents were reviewed and approved by institutional review boards and/or independent ethics committee at each study site.

The primary objective of the study was to assess the long-term safety and clinical outcome in patients treated with idursulfase. Safety and clinical outcomes were assessed every 4 months during the first year of the study and every 6 months thereafter. During the 2 years of the extension study, the primary outcome measures were 6MWT distance and FVC. The 6MWT was conducted according to the recommendations of the American Thoracic Society. Patients walked back and forth between markers placed $30 \mathrm{~m}$ apart, and the total distance covered in 6 minutes was recorded by an observer. FVC was measured by spirometry, according to standard methods, using the best effort of three determinations on that day. ${ }^{5,6}$ Percent predicted FVC (\%FVC) was calculated based on published reference standards based on height and age. ${ }^{7,8}$ Secondary outcome measures included measurement of liver and spleen volume (measured by magnetic resonance imaging), urine GAG excretion, cardiac mass (measured by echocardiography), joint range of motion (JROM, measured by goniometry), linear growth velocity, and functional status (Child Health Assessment Questionnaire Disability Index Score [CHAQ DIS]). The self-reported CHAQ questionnaire was completed by all patients aged 12 years or older, and the parent questionnaire was completed by all parents or guardians. The CHAQ is a validated instrument ${ }^{9}$ that assesses eight domains of physical function based on the responses to 30 questions and presents an overall summary score (standard disability index). Hepatomegaly was defined as a liver volume (L) $>3.5 \%,>2.2 \%$, and $>2.6 \%$ of body weight $(\mathrm{kg})$ in patients aged 5-12 years, 13-17 years, and >18 years, respectively. ${ }^{10}$ Splenomegaly was defined as a spleen volume greater than the 95th percentile of the normal distribution in children. ${ }^{11}$ For the goniometry measurements, an increase of $\geq 10^{\circ}$ range of motion was considered clinically important for the majority of joint motions, except for hip abduction and internal and external rotation, knee flexion and extension, and ankle dorsiflexion, where an increase of $\geq 5^{\circ}$ was considered clinically important. AEs were recorded continuously throughout the study. A clinical assessment was done at each study visit. The presence of antiidursulfase antibodies in plasma were detected by an enzyme-linked immunosorbent assay as described previously. ${ }^{4}$ Samples testing positive for IgG antibodies were further tested for neutralizing activity by an in vitro enzyme inhibition assay and by inhibition of cell uptake of idursulfase. An antibody-positive serum sample with $\geq 40 \%$ inhibition of enzyme activity was considered to have been positive for activity-based neutralizing antibody. Similarly, a sample was also considered neutralizing if the amount of idursulfase internalized by cells was reduced by $<23 \%$ compared with the effect of pooled normal human serum.

\section{Statistical methods}

This analysis includes results obtained from patients during treatment with idursulfase EOW or weekly during the original, double-blinded study ${ }^{4}$ combined with the results obtained during this 2-year, open-labeled extension study. For the purposes of this analysis, baseline was defined as the most recent assessment before the beginning of treatment with ERT. Thus, for patients who were in the original placebo group, baseline was defined as the final assessment in the double-blinded study. For both the weekly and the EOW $0.5 \mathrm{mg} / \mathrm{kg}$ groups, baseline was the last measurement before starting ERT in the double-blinded study. The change from baseline was analyzed with a paired $t$ test or a Wilcoxon signed-rank test, depending on the distribution of the data. In some cases, separate analyses were conducted for subgroups. All statistical calculations were performed with SAS version 9.1 (SAS Institute Inc., Cary, NC).

\section{RESULTS}

Table 1 presents the demographics and baseline characteristics of the study population. Ninety-four patients enrolled in the 2-year extension study, and 85 patients completed the end of study evaluations. One patient died of respiratory failure (see "Safety results"). Eight patients transferred to their home countries during the 2-year extension study and continued to receive idursulfase under the "named patient use" policy. On transfer to their home countries, these eight patients were withdrawn from the study because the follow-up evaluations could not be performed. These eight patients were equally distributed among the original treatment groups from the double-blinded study (idursulfase weekly, $n=2$; EOW, $n=3$; placebo, $n=3$ ). Compliance with treatment and testing was good among the enrolled patients; only two patients received $<80 \%$ of doses, and only five patients missed four or more consecutive doses.

\section{Efficacy}

The primary measures of clinical efficacy in this study were changes in FVC and 6MWT distance. Baseline of \%FVC was 
Table 1 Demographic and baseline characteristics

\begin{tabular}{|c|c|c|c|c|}
\hline \multirow[b]{2}{*}{ Treatment baseline characteristics } & \multicolumn{3}{|c|}{ Double-blinded treatment group } & \multirow[b]{2}{*}{ All patients } \\
\hline & Weekly & EOW & Placebo & \\
\hline$N$ & 31 & 32 & 31 & 94 \\
\hline Age (yr) & $14.8 \pm 1.11$ & $14.4 \pm 1.24$ & $14.4 \pm 1.24$ & $14.5 \pm 0.68$ \\
\hline Range (yr) & 6.3 to 26.0 & 5.4 to 30.9 & 6.0 to 30.0 & 5.4 to 30.9 \\
\hline \multicolumn{5}{|l|}{ Age category, $N(\%)$} \\
\hline $5-12 \mathrm{yr}$ & $14(45.2)$ & $14(43.8)$ & $13(41.9)$ & $41(43.6)$ \\
\hline $12-18 \mathrm{yr}$ & $10(32.3)$ & $9(28.1)$ & $10(32.3)$ & $29(30.9)$ \\
\hline $19-25 \mathrm{yr}$ & $6(19.4)$ & 7 (21.9) & $5(16.1)$ & $18(19.1)$ \\
\hline$\geq 26 \mathrm{yr}$ & $1(3.2)$ & $2(6.3)$ & $3(9.7)$ & $6(6.4)$ \\
\hline Height (cm) & $129 \pm 2.7$ & $128 \pm 2.6$ & $127 \pm 2.1$ & $128 \pm 1.4$ \\
\hline Weight (kg) & $37.6 \pm 2.4$ & $36.7 \pm 2.3$ & $35.7 \pm 2.2$ & $36.7 \pm 1.3$ \\
\hline Race (South American Indian/Asian/black/white/other) & $1 / 0 / 2 / 27 / 1$ & $2 / 2 / 1 / 27 / 0$ & $0 / 3 / 3 / 24 / 1$ & $3 / 5 / 6 / 78 / 2$ \\
\hline FVC (L) & $1.21 \pm 0.10$ & $1.17 \pm 0.10$ & $1.18 \pm 0.09$ & $1.18 \pm 0.05$ \\
\hline$\%$ Predicted FVC & $56.1 \pm 2.8$ & $55.1 \pm 2.4$ & $57.3 \pm 2.8$ & $56.2 \pm 1.5$ \\
\hline \multicolumn{5}{|l|}{$\%$ Predicted FVC Severity Score, $N(\%)$} \\
\hline Score 1 (mild, $\geq 70 \%$ to $<80 \%$ ) & $7(22.6)$ & $6(18.8)$ & $8(25.8)$ & $21(22.3)$ \\
\hline Score 2 (moderate, $\leq 50 \%$ to $<70 \%$ ) & $13(41.9)$ & $12(37.5)$ & $14(45.2)$ & $39(41.5)$ \\
\hline Score 3 (severe, $<50 \%$ ) & $11(35.5)$ & $14(43.8)$ & $9(29.0)$ & $34(36.2)$ \\
\hline 6MWT (m) & $401 \pm 17$ & $401 \pm 18$ & $399 \pm 19$ & $400 \pm 10$ \\
\hline \multicolumn{5}{|l|}{ 6MWT Severity Score, $N(\%)$} \\
\hline Score 1 (normal to mild, $\geq 500 \mathrm{~m}$ ) & $6(19.4)$ & $6(18.8)$ & $4(12.9)$ & $16(17.0)$ \\
\hline Score 2 (moderate, $\geq 300$ to $<500 \mathrm{~m}$ ) & $20(64.5)$ & $21(65.6)$ & $23(74.2)$ & $64(68.1)$ \\
\hline Score 3 (severe, $<300 \mathrm{~m}$ ) & $5(16.1)$ & $5(15.6)$ & $4(12.9)$ & $14(14.9)$ \\
\hline \multicolumn{5}{|l|}{ Disease Severity Score, $N(\%)^{a}$} \\
\hline Score 2 & $2(6.5)$ & $2(6.3)$ & $1(3.2)$ & $5(5.3)$ \\
\hline Score 3 & $7(22.6)$ & $6(18.8)$ & $8(25.8)$ & $21(22.3)$ \\
\hline Score 4 & $10(32.3)$ & $11(34.4)$ & $14(45.2)$ & $35(37.2)$ \\
\hline Score 5 & $10(32.3)$ & $9(28.1)$ & $5(16.1)$ & $24(25.5)$ \\
\hline Score 6 & $2(6.5)$ & $4(12.5)$ & $3(9.7)$ & $9(9.6)$ \\
\hline Liver volume $(\mathrm{mL})^{b}$ & $1261 \pm 52$ & $1191 \pm 48$ & $1186 \pm 58$ & $1213 \pm 30$ \\
\hline Spleen volume $(\mathrm{mL})^{b}$ & $320 \pm 41$ & $251 \pm 26$ & $303 \pm 32$ & $292 \pm 19$ \\
\hline Urine GAG ( $\mu \mathrm{g} / \mathrm{mg}$ creatinine) & $330 \pm 26$ & $338 \pm 21$ & $419 \pm 23$ & $362 \pm 14$ \\
\hline
\end{tabular}

Values are expressed as mean \pm SE unless otherwise indicated.

${ }^{a}$ Disease severity score is the sum of the 6MWT and \% predicted FVC severity scores.

${ }^{b}$ The number of patients who had treatment baseline liver and spleen volumes measured was 30, 29, and 29 in the double-blinded weekly, EOW, and placebo groups, respectively (total $=88$ ).

EOW, every other week; FVC, forced vital capacity; 6MWT, 6-minute walking test; GAG, glycosaminoglycan.

$56.2 \% \pm 1.5 \%$. Figure 1 shows the response of $\% \mathrm{FVC}$ during ERT. A statistically significant improvement in \%FVC was observed at a single time point during this study (Month 16). In contrast to the minimal change in $\% \mathrm{FVC}$, absolute FVC demonstrated sustained improvement throughout the study (Fig. 2). Baseline absolute FVC was $1.18 \pm 0.06 \mathrm{~L}$, and after 3 years, the increase in absolute $\mathrm{FVC}$ was $0.31 \pm 0.06 \mathrm{~L}$ or $25.1 \% \pm 4.0 \%$ $(P<0.05)$. The subgroups of patients younger than 12 years and patients aged between 12 and 18 years demonstrated substantial increases in absolute FVC. For example, at 36 months, the subgroup $<12$ years demonstrated an increase of $0.39 \pm$ $0.09 \mathrm{~L}$, and the subgroup between 12 and 18 years demonstrated 


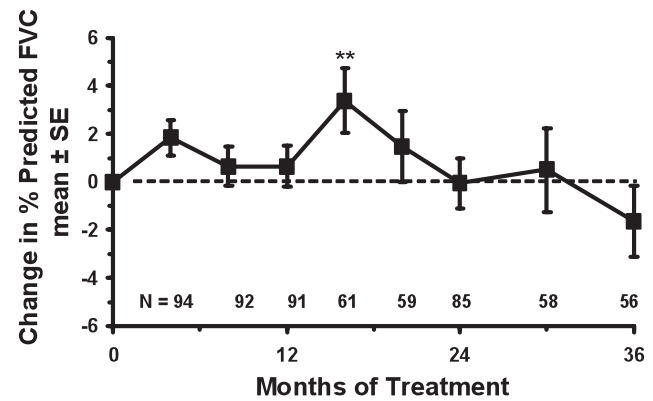

Fig. 1. The effect of idursulfase on percent predicted forced vital capacity (\% predicted FVC). Baseline \% predicted FVC $=56.2 \% \pm 1.5 \%$ (mean $\pm \mathrm{SE}$ ). ${ }^{*} P<0.01$.

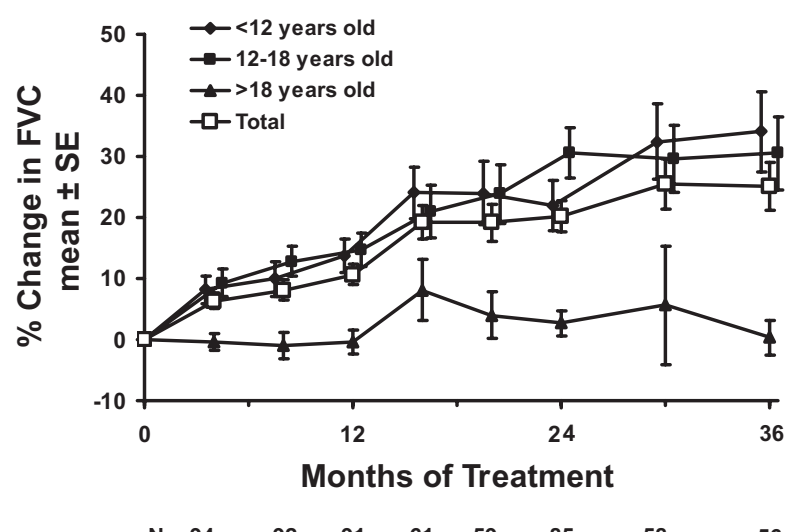

Fig. 2. The effect of idursulfase on absolute forced vital capacity (FVC). The data points for the $<12$-year-old and the 12-18-year-old subgroups are offset slightly for clarity. $N$ represents the total number of patients at each time point. $P<0.001$ compared with baseline for each value of the total population. No statistical testing was performed on the subgroups. Baseline FVC was $1.18 \pm 0.055 \mathrm{~L}$ (mean $\pm \mathrm{SE}$ ) for the total population and was $0.96 \pm 0.05$, $1.26 \pm 0.10$, and $1.47 \pm 0.14 \mathrm{~L}$ in the $<12$ years, $12-18$ years, and $>18$-year-old subgroups, respectively.

an increase of $0.45 \pm 0.11 \mathrm{~L}$. In the patients older than 18 years, a decrease of $0.04 \mathrm{~L}$ was seen at 36 months (Fig. 2).

Figure 3 shows improvement in 6MWT distance in the total study population as a function of time on treatment. The baseline for $6 \mathrm{MWT}$ distance in the entire study population was $400 \pm 10 \mathrm{~m}$. Positive changes in $6 \mathrm{MWT}$ were recorded at all time points, and these values were statistically significant at all but one time point. The mean increases ranged from $14 \pm 5 \mathrm{~m}$ at 4 months to $42 \pm 10 \mathrm{~m}$ at 20 months, corresponding to mean percent increases of $6.4 \% \pm 2.7 \%$ and $11.7 \% \pm 3.0 \%$ increases, respectively. The largest increases were seen in the patients older than 18 years $(n=24)$, who had a baseline 6MWT distance of $351 \pm 27 \mathrm{~m}$ and demonstrated a mean increase of $48 \pm 13 \mathrm{~m}$ at 36 months. The subgroup $<12$ years $(n=41)$ had a baseline $6 \mathrm{MWT}$ distance of $428 \pm 11 \mathrm{~m}$ and demonstrated an increase of $8 \pm 6 \mathrm{~m}$ at 36 months. The patients aged between 12 and 18 years $(n=29)$ had a baseline 6MWT distance of $403 \pm$ $18 \mathrm{~m}$ and demonstrated an increase of $0.7 \pm 7 \mathrm{~m}$ at 36 months.

Abnormal liver and spleen volumes were present in $79 \%$ of the patients at baseline. As shown in Figure 4, liver and spleen

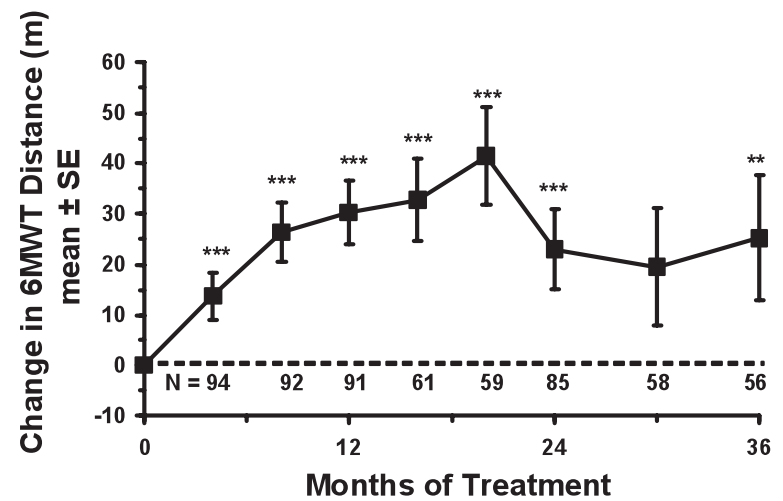

Fig. 3. Effect of idursulfase on 6-minute walking test (6MWT) distance. Baseline 6MWT distance $=400 \pm 10 \mathrm{~m}$ (mean $\pm \mathrm{SE}$ ). The dotted horizontal line represents the baseline. ${ }^{* *} P<0.01$; ${ }^{* *} P<0.001$.

volumes were significantly reduced after 4 months of treatment. These reductions were sustained throughout the study.

At baseline, 91 of 94 patients had urine GAG levels above the upper limit of normal (127 $\mu \mathrm{g} / \mathrm{mg}$ creatinine). The mean urine GAG level at the beginning of treatment was $362 \pm 14$ $\mu \mathrm{g} / \mathrm{mg}$ creatinine, a value 3 -fold greater than the upper limit of normal. At 4 months, the mean value declined to $156 \pm 9$ $\mu \mathrm{g} / \mathrm{mg}$ creatinine $(P<0.001)$, and at 16 months, the mean value had fallen to $107 \pm 9 \mu \mathrm{g} / \mathrm{mg}$ creatinine, a value below the level of the upper limit of normal. At Month 36, the mean GAG level was reduced to $81.7 \mu \mathrm{g} / \mathrm{mg}$ creatinine. At final study visit, only 31 of 94 patients had urine GAG levels above the upper limit of normal.

Progressive, statistically significant, and clinically important improvements in JROM were seen only for the shoulder (Fig. 5). No consistent change in function was observed for elbow, wrist, digits, hip, knee, or ankle.

Linear growth velocity in the 15 patients who were prepubertal (defined as not yet reaching Tanner Stage 2) throughout the study was $4.33 \mathrm{~cm} /$ year. No effect of the duration of ERT on growth was apparent (data not shown). At baseline, the mean height of the patients who were younger than 12 years $(n=41)$ was $120 \pm 1.5 \mathrm{~cm}$, and after 36 months of ERT, height had increased by a mean of $11.9 \pm 1.0 \mathrm{~cm}$. The mean growth velocities at individual time points ranged from 3.71 to 4.48 $\mathrm{cm} /$ year over 36 months. In the group of patients aged between 12 and 18 years $(n=26)$, mean height was $128 \pm 2.2 \mathrm{~cm}$, and after 36 months, height had increased by a mean of $9.8 \pm 1.4$ $\mathrm{cm}$. The mean growth velocities at individual time points ranged from 3.04 to $4.38 \mathrm{~cm} /$ year over 36 months. In contrast to the growth seen in the younger patients, the patients older than 18 years demonstrated minimal change in stature. At baseline, mean height was $140 \pm 2.5 \mathrm{~cm}$, and after 36 months, height had increased by a mean of $1.2 \pm 0.4 \mathrm{~cm}$. Mean growth velocity at individual time points was $<1.11 \mathrm{~cm} /$ year.

The CHAQ was used to collect data on the functional status of patients with Hunter syndrome on their ability to perform daily physical activities. Scores range from 0 (no problem) to 3 (unable to perform), and changes of -0.13 to -0.25 are considered to be clinically important improvements in function. ${ }^{12,13}$ The standard parent-assessed DIS at baseline was $1.50 \pm 0.71$ $(n=81$, mean $\pm \mathrm{SE})$, and statistically significant improvements were seen at months $8,16,20,24$, and 30 . For example, at 24 months, the parent-assessed DIS had declined by $-0.13 \pm$ 

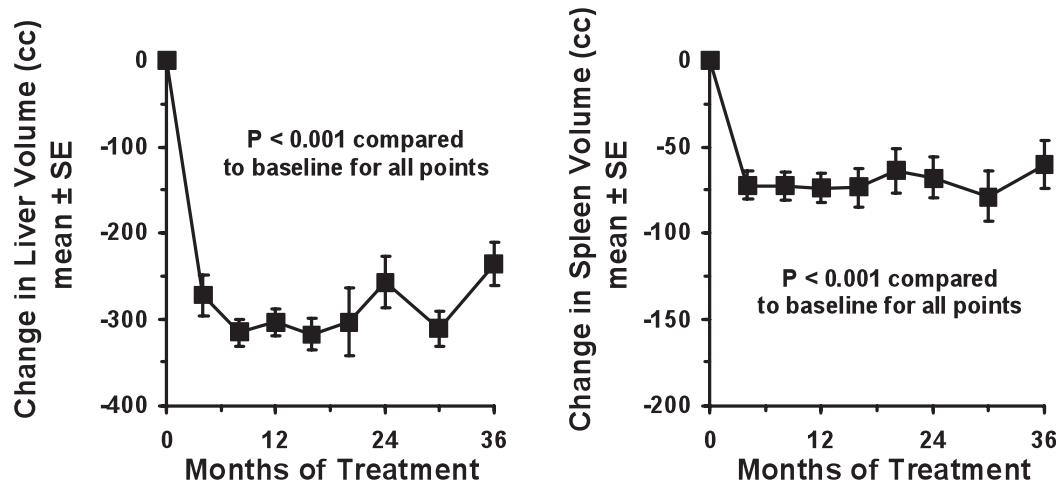

Fig. 4. The effect of idursulfase on liver and spleen volumes. Baseline liver volume $=1213 \pm 30 \mathrm{~L}$ (mean $\pm \mathrm{SE}$ ). Baseline spleen volume $=292 \pm 19 \mathrm{~L}$.

Shoulder Abduction

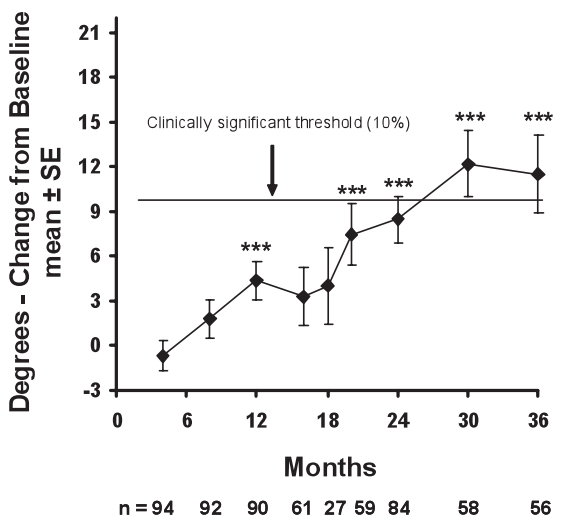

Shoulder Flexion-Extension

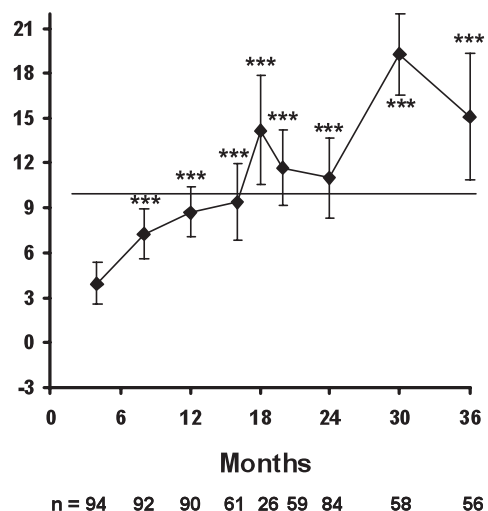

Fig. 5. Passive joint range of motion results for shoulder during treatment with idursulfase. ${ }^{* \star} P \leq 0.005$ compared with baseline.

$0.064(P=0.047)$. The child-assessed CHAQ was completed by 48 children at baseline, and their standard DIS was $1.28 \pm$ 0.10 . Statistically significant improvements in the child-assessed standard DIS were seen at Months 20, 24, 30, and 36. For example, after 24 months, the child-assessed CHAQ had improved by $-0.15 \pm 0.65(n=44, P=0.031)$. Statistically significant improvements for the hygiene $(-0.3 \pm 0.12)$ and reach $(-0.4 \pm 0.13)$ domains were seen at 24 months. The improvement in the reach domain remained statistically significant up until the final measurement at Month 36.

\section{Safety results}

AEs of varying severity were reported by all patients. Fiftysix patients $(59.6 \%)$ experienced at least 1 drug-related AE (Table 2). Treatment-related AEs were more common in patients who were in the original placebo group $(23 / 31,74.2 \%)$ than in the weekly dose $(18 / 31,58.1 \%)$ or EOW groups $(15 / 32$, $46.9 \%)$. A total of 27 patients $(28.7 \%)$ experienced at least one severe or life-threatening AE. Severe AEs that occurred in two or more patients included bacteremia $(n=2)$, otitis media chronic $(n=2)$, carpal tunnel syndrome $(n=6)$, obstructive airway disorder $(n=2)$, sleep apnea $(n=2)$, and abdominal strangulated hernia $(n=2)$. The life-threatening AE was an obstructive airway disorder. This 21-year-old patient had been treated with weekly idursulfase $(0.5 \mathrm{mg} / \mathrm{kg})$ for approximately 14 months when he was hospitalized due to an exacerbation of asthma. Five days later, he was discharged but was readmitted after 1 day due to hematemesis, which was found to be caused by stomach herniation into an umbilical hernia. He experienced an acute episode of desaturation and was admitted to an intensive care unit and placed on a ventilator. Approximately 1 week later during an exchange of the endotracheal tube, it was found that his right main bronchus was completely occluded, and his left main bronchus was $75 \%$ occluded. He died during a computed tomography scan before the planned tracheal stenting. The cause of death was reported as upper airway obstruction and mucus plugging. This death was not considered to be related to treatment by the investigators. Overall rates of AEs, serious AEs, and severe or life-threatening AEs were similar in all prior treatment groups.

A total of 50 patients $(53 \%)$ experienced at least one infusion-related $\mathrm{AE}$ in the extension study, with the incidence during the extension study being higher in the group originally treated with placebo $(74.2 \%)$ compared with the groups originally treated with weekly (45.2\%) or EOW (40.6\%) idursulfase. The three most common infusion-related AEs were headache $(16 \%)$, urticaria $(11.7 \%)$, and pyrexia $(8.5 \%)$. The incidence of infusion-related AEs peaked at about Month 3 of treatment and declined thereafter as shown in Figure 6.

\section{Antibodies}

A patient was considered antibody positive if antiidursulfase antibodies were detected at any time during the double-blinded or open-labeled extension studies. Forty-seven patients $(50 \%)$ 
Table 2 Most common adverse events considered possibly or probably drug related

\begin{tabular}{|c|c|c|c|c|}
\hline \multirow[b]{2}{*}{ System organ class preferred term } & \multicolumn{3}{|c|}{ Double-blinded treatment group (\%) } & \multirow[b]{2}{*}{ Total $(N=94)$} \\
\hline & Weekly $(N=31)$ & EOW $(N=32)$ & Placebo $(N=31)$ & \\
\hline Any system organ class & $18(58.1)$ & $15(46.9)$ & $23(74.2)$ & $56(59.6)$ \\
\hline Nervous system disorder & $8(25.8)$ & $7(21.9)$ & $10(32.3)$ & $25(26.6)$ \\
\hline Headache & $6(19.4)$ & $5(15.6)$ & $6(19.4)$ & $17(18.1)$ \\
\hline Vascular disorders & $5(16.1)$ & $2(6.3)$ & $7(22.6)$ & $14(14.9)$ \\
\hline Flushing & $1(3.2)$ & $2(6.3)$ & $4(12.9)$ & $7(7.4)$ \\
\hline Skin and subcutaneous tissue disorders & $4(12.9)$ & $5(15.6)$ & $15(48.4)$ & $24(25.5)$ \\
\hline Urticaria NOS & $2(6.5)$ & $2(6.3)$ & $7(22.6)$ & $11(11.7)$ \\
\hline Erythema & $1(3.2)$ & $1(3.1)$ & $5(16.1)$ & $7(7.4)$ \\
\hline Pruritus & $2(6.5)$ & $1(3.1)$ & $4(12.9)$ & $7(7.4)$ \\
\hline Rash NOS & $1(3.2)$ & $1(3.1)$ & $4(12.9)$ & $6(6.4)$ \\
\hline General disorders & $5(16.1)$ & $5(15.6)$ & $10(32.3)$ & $20(21.3)$ \\
\hline Pyrexia & $3(9.7)$ & $2(6.3)$ & 4 (12.9) & $9(9.6)$ \\
\hline
\end{tabular}

Only adverse events that occurred in $\geq 10 \%$ of patients in any of the three treatment groups of the initial double-blinded study (idursulfase weekly, idursulfase EOW, or

EOW, every other week; NOS, not otherwise specified.

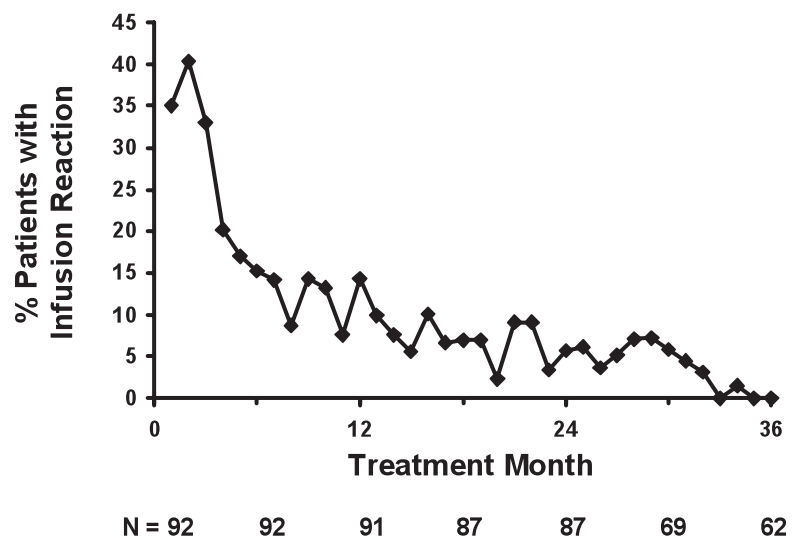

Fig. 6. Incidence of infusion reactions during treatment with idursulfase.

were positive for IgG antibodies at some time during the double-blinded or extension studies. At the end of the extension study, 23 of 85 patients (27.1\%) were IgG positive. At any time during the study, 22 of $94(23.4 \%)$ patients had neutralizing antibodies, and after 105 weeks, neutralizing antibodies were detected in 19 of $85(22.3 \%)$ patients, suggesting that tolerization had not occurred. The development of neutralizing antibodies seems to be a significant factor in the long-term drug response. The increase in absolute FVC was higher in patients who were neutralizing antibody negative $(n=72$, mean increase at individual time points ranged from 6.7 to $31.8 \%$ ) than in patients who were neutralizing antibody positive $(n=22$, mean increase at individual time points ranged from 2.3 to $12.7 \%$ ). Patient responses on 6MWT, liver and spleen volume, and urine GAG levels were not affected by the neutralizing antibody status. No IgE antibodies were detected at any time during the study.

\section{DISCUSSION}

This study represents the largest and longest study of ERT in the treatment of Hunter syndrome. The results extend the observations of the double-blinded study ${ }^{4}$ in an open-labeled extension phase for 2 additional years and demonstrate the sustained benefits of idursulfase treatment. Significant and sustained improvements in absolute FVC and 6MWT compared with baseline were observed. Decreases in liver and spleen volumes observed in the first phase of the study were maintained during the extension phase. Urine GAG levels showed a continuous decrease during the 3 years of treatment. Improvements were also seen in parameters of joint movement and measurement of quality of life. The most common treatmentrelated AEs were infusion-related headache, pyrexia, and urticaria. Overall, the study demonstrates the benefits of continuous treatment with idursulfase during a 3-year period.

During the double-blinded study, mean \%FVC increased from 55.3 to $\sim 58.8 \%$ in the $0.5 \mathrm{mg} / \mathrm{kg}$ weekly group, but the increase was not statistically significant $(P=0.07)$. In the present analysis, no change in $\% \mathrm{FVC}$ was evident. The formulae for $\% \mathrm{FVC}$ assume both normal growth and height ${ }^{7,8}$ neither of which applies to patients with Hunter syndrome. The height of patients older than 9 years in this study was below the 5 th percentile for age. ${ }^{4}$ The persistent improvement observed in absolute FVC supports beneficial effects of idursulfase on pulmonary function. The increases in absolute FVC observed during the study may reflect growth that occurred in the younger patients during treatment with idursulfase, because no change in absolute FVC was observed in the subgroup of patients older than 18 years, who had no significant growth.

Hepatosplenomegaly is a consistent feature of Hunter syndrome. Liver and spleen volumes showed consistent decreases during treatment with idursulfase that were independent of antibody status. Reduced liver size may contribute to improved diaphragmatic movements, pulmonary function, and gastroin- 
testinal comfort, leading to increased capabilities for physical activities and better quality of life.

Patients with Hunter syndrome historically have short stature, and it is the experience of the investigators that most patients with Hunter syndrome have a strong desire to be taller. Although no control group was included in this study, the growth velocity observed in prepubertal patients $(4.33 \mathrm{~cm} /$ year), as well as in the patients younger than 12 years who demonstrated similar growth velocity during idursulfase treatment, suggests that in some patients growth rates approaching those seen in the age-matched general population may be achieved (approximately $5-6 \mathrm{~cm} /$ year). ${ }^{14}$

Joint stiffness is a common symptom in patients with Hunter syndrome ${ }^{15}$ and contributes to difficulties in performing activities of daily living. The JROM results demonstrated consistent improvement for combined shoulder flexion/extension and shoulder abduction (Fig. 5), but no improvement was seen for other joints. The improvements in shoulder movement are reflected in the results of the CHAQ self-assessment of functional status that showed persistent significant improvement in "reach" beginning at 20 months.

The safety profile of idursulfase was similar to that reported for ERT of other lysosomal storage diseases..$^{10,16-21}$ Importantly, the incidence of infusion reactions decreased during the course of up to 3 years of treatment. Up to $50 \%$ of patients developed IgG antibodies at some time during the study, but immunological tolerance was occurring at the end of the study. However, no tolerization was evident in patients with neutralizing antibodies, an observation that is important because neutralizing antibodies seemed to attenuate the increase in absolute FVC.

\section{Study limitations}

This study design was open-labeled, and the lack of a concurrently followed placebo group limits the strength of the observations, because the progression of the disease is variable and has not been well described.

\section{CONCLUSION}

The results of this study greatly expand the experience with idursulfase for the treatment of Hunter syndrome. Reductions in urine GAG and hepatosplenomegaly and the clinically meaningful benefits observed during the double-blinded study were sustained during the open-labeled extension study. Continued clinical effectiveness of idursulfase is documented by improved lung function, the increased 6MWT distance, improved shoulder range of motion, and improvements in quality of life. It is important to note that even stabilization of clinical disease in patients with Hunter syndrome is significant, because it is a progressive lysosomal storage disorder. No new safety issues were observed, and infusion-related reactions declined significantly with continued idursulfase treatment. The long-term impact of neutralizing antibodies will need to be monitored. In summary, long-term continued weekly treatment of idursulfase is beneficial, and clinical disease has been stabilized and/or improved, which has resulted in an improved quality of life for patients with Hunter syndrome.

\section{ACKNOWLEDGMENTS}

This project was supported in part by Grant M01RR00046 from the National Center of Research Resources, National Institutes of Health (J.M.). This study was supported, in part, with funds provided by the National Center for Research Resources, 5 M01 RR-01271 (P.H.). The content is solely the responsibility of the authors and does not necessarily represent the official views of the National Center for Research Resources or the National Institutes of Health.

This study was conducted by Shire HGT, who was responsible for all statistical analyses. Shire HGT paid for editorial assistance to the authors provided by Thresia Thomas, $\mathrm{PhD}$, and Edward Weselcouch, PhD, of PharmaWrite, LLC (Princeton, NJ). The authors participated fully in the preparation of the manuscript and are fully responsible for its content.

\section{REFERENCES}

1. Bach G, Eisenberg F Jr, Cantz M, Neufeld EF. The defect in the Hunter syndrome: deficiency of sulfoiduronate sulfatase. Proc Natl Acad Sci USA 1973;70:2134-2138.

2. Neufeld EF, Muenzer J. The mucopolysaccharidoses. In: Scriver C, Beaudet A, Sly W, Valle D, editors. The metabolic and molecular bases of inherited diseases. New York: McGraw-Hill, 2001:3421-3452.

3. Martin R, Beck M, Eng C, et al. Recognition and diagnosis of mucopolysaccharidosis II (Hunter syndrome). Pediatrics 2008;121:e377-e386.

4. Muenzer J, Wraith JE, Beck M, et al. A phase II/III clinical study of enzyme replacement therapy with idursulfase in mucopolysaccharidosis II (Hunter syndrome). Genet Med 2006;8:465-473.

5. Quanjer PH, Tammeling GJ, Cotes JE, Pedersen OF, Peslin R, Yernault JC. [Lung volumes and forced ventilatory flows. Work Group on Standardization of Respiratory Function Tests. European Community for Coal and Steel. Official position of the European Respiratory Society.] Rev Mal Respir 1994;11(suppl 3):5-40.

6. Quanjer PH, Tammeling GJ, Cotes JE, Pedersen OF, Peslin R, Yernault JC. Lung volumes and forced ventilatory flows. Report Working Party Standardization of Lung Function Tests, European Community for Steel and Coal. Official Statement of the European Respiratory Society. Eur Respir J Suppl 1993;16:5-40.

7. Hankinson JL, Odencrantz JR, Fedan KB. Spirometric reference values from a sample of the general U.S. population. Am J Respir Crit Care Med 1999;159:179-187.

8. Polgar G, Promadhat V. Pulmonary function testing in children: techniques and standards. Philadelphia: W.B. Saunders and Company, 1971

9. Singh G, Athreya BH, Fries JF, Goldsmith DP. Measurement of health status in children with juvenile rheumatoid arthritis. Arthritis Rheum 1994;37: 1761-1769.

10. Kakkis ED, Muenzer J, Tiller GE, et al. Enzyme-replacement therapy in mucopolysaccharidosis I. N Engl J Med 2001;344:182-188.

11. Schlesinger AE, Edgar KA, Boxer LA. Volume of the spleen in children as measured on CT scans: normal standards as a function of body weight. AJR Am J Roentgenol 1993;160:1107-1109.

12. Flato B, Sorskaar D, Vinje O, et al. Measuring disability in early juvenile rheumatoid arthritis: evaluation of a Norwegian version of the childhood Health Assessment Questionnaire. J Rheumatol 1998;25:1851-1858.

13. Dempster H, Porepa M, Young N, Feldman BM. The clinical meaning of functional outcome scores in children with juvenile arthritis. Arthritis Rheum 2001;44:1768-1774

14. Kuczmarski RJ, Ogden CL, Guo SS, et al. 2000 CDC Growth Charts for the United States: methods and development. Vital Health Stat 11 2002;1-190.

15. Wraith JE, Beck M, Giugliani R, Clarke J, Martin R, Muenzer J. Initial report from the Hunter Outcome Survey (HOS). Genet Med 2008;10:508-516.

16. Wraith JE, Tylki-Szymanska A, Guffon N, et al. Safety and efficacy of enzyme replacement therapy with agalsidase beta: an international, open-label study in pediatric patients with Fabry disease. J Pediatr 2008;152:563-570.

17. Wraith JE, Scarpa M, Beck M, et al. Mucopolysaccharidosis type II (Hunter syndrome): a clinical review and recommendations for treatment in the era of enzyme replacement therapy. Eur J Pediatr 2008;167:267-277.

18. Harmatz P, Giugliani R, Schwartz IV, et al. Long-term follow-up of endurance and safety outcomes during enzyme replacement therapy for mucopolysaccharidosis VI: final results of three clinical studies of recombinant human N-acetylgalactosamine 4-sulfatase. Mol Genet Metab 2008;94:469-475.

19. Harmatz P, Giugliani R, Schwartz I, et al. Enzyme replacement therapy for mucopolysaccharidosis VI: a phase 3, randomized, double-blind, placebocontrolled, multinational study of recombinant human $\mathrm{N}$-acetylgalactosamine 4-sulfatase (recombinant human arylsulfatase B or rhASB) and follow-on, open-label extension study. J Pediatr 2006;148:533-539.

20. Harmatz P, Ketteridge D, Giugliani R, et al. Direct comparison of measures of endurance, mobility, and joint function during enzyme-replacement therapy of mucopolysaccharidosis VI (Maroteaux-Lamy syndrome): results after 48 weeks in a phase 2 open-label clinical study of recombinant human $\mathrm{N}$-acetylgalactosamine 4-sulfatase. Pediatrics 2005;115:e681-e689.

21. Ries M, Clarke JT, Whybra C, et al. Enzyme-replacement therapy with agalsidase alfa in children with Fabry disease. Pediatrics 2006;118:924932. 